\title{
SCIENTIFIC REPORTS

\section{OPEN Changing patterns and influencing factors of involuntary admissions following the implementation of China's mental health law: A 4-year longitudinal investigation}

Hua-Jian $\mathrm{Ma}^{1,2}$, Bin Xie ${ }^{1,2}$, Yang Shao ${ }^{1}$, Jing-Jing Huang ${ }^{1}$ \& Ze-Ping Xiao ${ }^{1 *}$

Involuntary admission (IA) is limited to particular situations in mental health laws to protect patients from unnecessary coercion. China's first national mental health law has been in effect since 2013; however, the status of IA has not been sufficiently explored. To explore the changing patterns of IA since the clinical application of the IA criteria specified in the new law, an investigation of IA status was undertaken in 14 periods (each period lasting for one month from 05/2013 to 05/2017) in the tertiary specialized psychiatric hospital in Shanghai. The socio-demographic and clinical characteristics of 3733 patients were collected. The differences among IA rates in different periods were compared, and the characteristics of patients who were and were not involuntarily admitted were analysed. Multiple logistic regression analysis was used to clarify the independent variables of IA. The IA rate dramatically decreased after the implementation of the new law, while the overall trend gradually increased. The implementation of the IA risk criteria is effective, but IA is still common in China. The medical factors influencing IA following the implementation of the new law are similar to those in previous studies at home and abroad. Non-medical factors might be the main causes of the high IA rates in Chinese psychiatric institutions.

Although it is a controversial topic because of the infringement on basic human rights and low levels of treatment satisfaction ${ }^{1-3}$, involuntary hospital admission is still a necessary measure in the management of mentally ill individuals who lack insight ${ }^{4,5}$. Mental health services in China were mostly provided by specialized psychiatric hospitals, including all kinds of psychiatric patients. Clinical practice in such institutions was based on diagnostic criteria such as the International Classification of Diseases (ICD-10) and therapeutic guidelines. The entire system was organized as more medically or clinically oriented than patients' rights oriented. Previous studies reported that the IA rate in China was much higher than that in Western countries ${ }^{6-9}$. This difference was attributed to both social factors and, importantly, the lack of national legislation or standards regarding involuntary psychiatric hospitalization.

China's first national mental health law - the Mental Health Law of the People's Republic of China - was enacted on May 1st, 2013, after 27 years of debate and wide-ranging discussion at different levels ${ }^{10}$. Especially after the ratification of the International Covenant on Civil and Political Rights (ICCPR) and the International Covenant on Social, Economic and Cultural Rights (ICSECR) in the mid-1990s, coercion involving psychiatric services in China received more attention. Later, drafts of the law referred to international documents such as the United Nations General Assembly $(46 / 119)^{11}$ and Mental Health Care Law: Ten Basic Principles ${ }^{12}$. Minimum restrictions, autonomy, and informed consent were largely reflected in this legislation.

Given the complex factors involved, such as the need to protect the autonomy of mentally ill individuals, the traditions of China's mental health services, and other socio-cultural variables, the drafters of the law replaced the broader 'need for treatment' criteria with much stricter risk-based criteria. The latter had been pilot-tested in local jurisdictions around China before being included in the national law. Specifically, '...the medical facility may

\footnotetext{
${ }^{1}$ Shanghai Mental Health Center, Shanghai Jiao Tong University School of Medicine, Shanghai, 200030, P.R. China.

2These authors contributed equally: Hua-Jian Ma and Bin Xie. *email: xiaozeping88@163.com
} 


\begin{tabular}{|c|c|c|c|c|c|}
\hline \multirow[b]{2}{*}{ Serial number } & \multirow[b]{2}{*}{ Time period after the legislation } & \multicolumn{2}{|c|}{ Voluntary admission $(n=755)$} & \multicolumn{2}{|c|}{ Involuntary admission $(\mathrm{n}=2978)$} \\
\hline & & $\mathbf{N}$ & $\%$ & $\mathbf{N}$ & $\%$ \\
\hline 1 & $1^{\text {st }}$ month (2013.05.01-2013.05.31) & 74 & 30.3 & 170 & 69.7 \\
\hline 2 & $2^{\text {nd }}$ month (2013.06.01-2013.06.30) & 72 & 29.1 & 175 & 70.9 \\
\hline 3 & $3^{\text {rd }}$ month (2013.07.01-2013.07.31) & 80 & 28.0 & 206 & 72.0 \\
\hline 4 & $4^{\text {th }}$ month (2013.08.01-2013.08.31) & 59 & 25.7 & 171 & 74.3 \\
\hline 5 & $5^{\text {th }}$ month (2013.09.01-2013.09.30) & 51 & 21.0 & 192 & 79.0 \\
\hline 6 & $6^{\text {th }}$ month (2013.10.01-2013.10.31) & 52 & 20.2 & 206 & 79.8 \\
\hline 7 & $7^{\text {th }}$ month (2013.11.01-2013.11.30) & 53 & 19.6 & 217 & 80.4 \\
\hline 8 & $8^{\text {th }}$ month (2013.12.01-2013.12.31) & 44 & 15.6 & 238 & 84.4 \\
\hline 9 & $9^{\text {th }}$ month (2014.01.01-2014.01.31) & 48 & 18.8 & 207 & 81.2 \\
\hline 10 & $10^{\text {th }}$ month (2014.02.01-2014.02.28) & 45 & 18.1 & 203 & 81.9 \\
\hline 11 & $11^{\text {th }}$ month (2014.03.01-2014.03.31) & 46 & 16.1 & 240 & 83.9 \\
\hline 12 & $12^{\text {th }}$ month (2014.04.01-2014.04.30) & 45 & 14.9 & 258 & 85.1 \\
\hline 13 & $30^{\text {th }}$ month (2015.10.01-2015.10.31) & 49 & 17.6 & 229 & 82.4 \\
\hline 14 & $49^{\text {th }}$ month (2017.05.01-2017.05.31) & 37 & 12.2 & 266 & 87.8 \\
\hline
\end{tabular}

Table 1. Pattern of IA frequency.

impose inpatient treatment if the individual meets one of the following conditions: (1) self-harm in the immediate past or risk of self-harm; (2) behaviour that harmed others or endangered the safety of others in the immediate past or risk to the safety of others ${ }^{10}$. In limiting involuntary admission to particular situations, the national law aimed to reduce the risk of infringing on the rights of patients and the occurrence of unreasonable IA in China.

Before the enactment of the new law, there were several investigations of the IA patterns in China, all of which found that IA is common in Chinese psychiatric hospitals. A multi-centre survey in $2002^{6}$ involving 17 cities and 2333 patients indicated that only $18.5 \%$ of psychiatric patients were voluntarily admitted. Another study of 161 patients in 2012 found an IA rate of $53.1 \%^{7}$. The IA rates in other investigations with small sample sizes were generally above $60 \%{ }^{13}$. These studies also found that IA in China is associated with factors similar to those in Western countries ${ }^{6,7,13,14}$, including aggressive behaviour, poor social functioning, and lack of insight. However, the situation since the new law took effect is still unclear.

Shanghai, a city with relatively abundant medical resources, was the first area in China to enact local mental health regulations. A 'need for treatment criterion' for IA in this legislation had been applied for more than ten years before the implementation of the new, much more restrictive risk-based criteria. The change in IA legislation in Shanghai was significant and far-reaching. We can learn more about the IA pattern from an investigation in Shanghai because Shanghai is a typical city with a clear and dramatic shift in IA legislation. The present study analyses the rate of IA and identifies the factors associated with IA following the new law's implementation in Shanghai. This study may provide supporting evidence to improve the design of the policy system and help explore possible trends and directions for future research in this area.

\section{Results}

Of the 3864 patients admitted to the hospital during the study period, $3733(96.6 \%)$ met the study criteria and participated in the study. Among the 3733 participants in the study, 2978 (79.8\%) patients were involuntarily admitted, and 755 patients $(20.2 \%)$ were voluntarily admitted. Male patients accounted for $44.7 \%(n=1669)$ of all admissions and $44.3 \%(n=1319)$ of involuntary admissions. No relationship was found between gender and admission status $(\mathrm{p}=0.308)$. The mean age was 42.39 years (standard deviation [SD] 18.95). A diagnosis of schizophrenia was the most common $(52.0 \%, \mathrm{~N}=1940)$, followed by mood disorders $(30.2 \%, \mathrm{~N}=1127)$.

Description of the voluntary and involuntary admission patterns. The pattern of voluntary and involuntary admission status is shown in Table 1 and Fig. 1. In general, the IA rate rose over time. It reached the highest point (87.8\%) 49 months after the new law took effect, and the lowest rate of IA (69.7\%) occurred in the first month after the law took effect.

Demographic and clinical characteristics of the voluntary and involuntary admission groups. The demographic and clinical characteristics of the 755 voluntarily admitted patients were compared to those of the 2978 involuntarily admitted patients (Tables 2 and 3). The IA patients were significantly more likely to be under 44 years old, to be unemployed, to be single (unmarried, divorced or widowed), to have health insurance, to lack insight, to have been hospitalized more times and to have been diagnosed with schizophrenia.

Predictors of admission status. Table 4 presents the results of a forward stepwise multivariate logistic regression analysis that simultaneously considered all the factors significantly related to involuntary admission, which was the dependent variable (Tables 2 and 3). The independent variables entered in the model were age, occupation, marital status, insurance, risk behaviours, insight, initial diagnosis, and number of hospitalizations. Predictors of involuntary admission in this model were under age 44 or above age 60 , single status, poor insight, diagnosis of schizophrenia or other psychotic illness, risk behaviours, and a higher number of hospitalizations. 


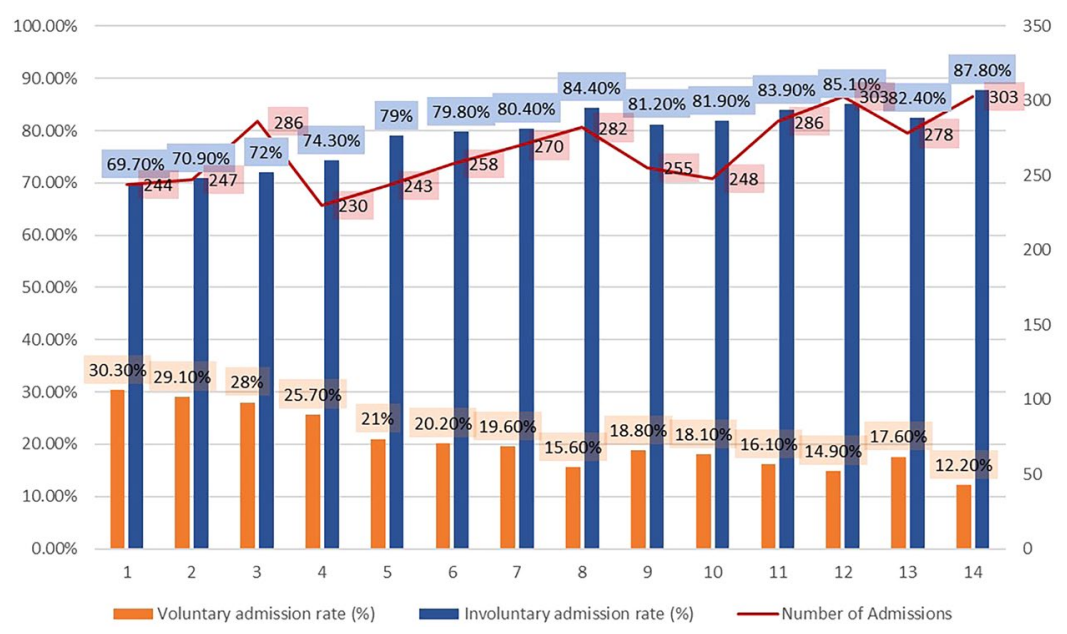

Figure 1. Histogram showing the pattern of IA, including the voluntary admission rate (\%), involuntary admission rate (\%) and number of admissions each month.

The $\mathrm{R}^{2}$ of this model was 0.489 , which means that $48.9 \%$ of the variance in admission status could be explained by variables in this model.

\section{Discussion}

As the medical records system showed, the percentage of IA patients in Shanghai Mental Health Center (SMHC) was slightly higher than the average $(81.5 \%)^{6}$ before the enactment of the national mental health law. The relatively high IA rate was related to the characteristics of SMHC, which is the only tertiary specialized psychiatric hospital in Shanghai and which provides first aid in psychiatric emergencies. Although the rate of IA declined sharply once the new legislation came into effect, the vast majority of psychiatric admissions remain involuntary. The IA rate after the new law is still much higher than those (3-50\%) reported in Western countries and has risen gradually over time $e^{3,8,15}$.

In fact, the change in IA patterns after the new law came into effect in China was similar to that in Western countries. Research in Western countries found that legislation did not affect the IA rate as much as policy makers had hoped and that there might be a relatively weak effect of legislation on clinical practice or even a gradual return to pre-legislation status ${ }^{15,16}$; this may also be the case here. The IA rate declined rapidly under the influence of the new regulation; however, it rose gradually due to a lack of supporting measures following the law, such as detailed operational procedures on IA and sufficient community-based services. The mechanism had characteristics that were similar to those of the deinstitutionalization and reinstitutionalization of psychiatric services in some Western countries ${ }^{17}$.

Generally, the factors affecting the IA pattern could be divided into two categories: medical and non-medical. Medical factors refer to the conditions of psychiatric patients, such as their demographic and clinical features, while non-medical factors are the procedures and specific operations in the process of IA decision-making and even the traditional culture and development of the entire society.

As found in this study, the medical factors influencing IA were quite similar to those found in previous studies, such as poor insight ${ }^{7,18}$, history of hospitalization ${ }^{19,20}$, aggressive or self-harm behaviour ${ }^{6,7,17,21}$, and diagnoses of schizophrenia or other psychotic illness ${ }^{4,9,15}$. As stipulated in the dangerousness admission criteria of the new law, there was a significant association between patients' aggressive or self-harm behaviour and IA. Except for the factors mentioned above, we found that single status was also significantly associated with patients' IA status. Previous studies have shown that unmarried status is a risk factor for frequent hospitalization in patients with mental disorders ${ }^{20,22,23}$, as it may delay timely treatment due to insufficient daily care and increase the possibility of readmission, or it may indicate poorer social capability and more severe psychiatric symptoms of the patients, leading to necessary treatment. Additionally, we noted that patients under age 44 or above age 60 were more likely to be involuntarily admitted. This result may differ from the findings of prior studies, in which involuntarily admitted patients were comparatively older or younger in age $e^{24,25}$. This discrepancy may be partly attributed to the different diagnoses and treatment needs of the two age groups. The majority of younger patients are diagnosed with schizophrenia, which is correlated with $\mathrm{IA}^{4,9,15}$; however, elderly patients are mostly diagnosed with dementia, and the majority have poor insight, which is also significantly related to $\mathrm{IA}^{7,18}$. Furthermore, the ageing of the population may aggravate this situation.

Although $48.9 \%$ of the variance in admission status could be explained by medical factors in the final model (Table 4), more than half of the variance should be attributed to other factors. The medical factors in IA after the new law were generally similar to those found in studies at home and abroad. That is, non-medical factors were the main causes of the high numbers of IA patients in Chinese psychiatric institutions.

First, in terms of medical resources, the high IA rate may be partially explained by the relative lack of community-based mental health services and the stigma experienced by patients and their family members ${ }^{26-31}$. Second, on the legislative and operational levels, the phrase 'risk to the safety of oneself/others' in the law leaves 


\begin{tabular}{|c|c|c|c|c|c|c|c|}
\hline & \multicolumn{2}{|c|}{$\begin{array}{l}\text { Voluntary } \\
\text { admission } \\
(\mathbf{n}=755)\end{array}$} & \multicolumn{2}{|c|}{$\begin{array}{l}\text { Involuntary } \\
\text { admission } \\
(\mathbf{n}=\mathbf{2 9 7 8 )}\end{array}$} & \multicolumn{3}{|l|}{ Statistics } \\
\hline & $\mathbf{N}$ & $\%$ & $\mathbf{N}$ & $\%$ & $\mathrm{X}^{2}$ & df & $P$ \\
\hline Gender: Male & 350 & 46.4 & 1319 & 44.3 & 1.040 & 1 & 0.308 \\
\hline Age (years) & & & & & 22.057 & 2 & 0.000 \\
\hline$\leq 44$ & 479 & 63.4 & 1764 & 59.2 & & & \\
\hline $45-59$ & 167 & 22.1 & 559 & 18.8 & & & \\
\hline$\geq 60$ & 109 & 14.4 & 655 & 22.0 & & & \\
\hline Occupation: unemployed & 507 & 67.2 & 2181 & 73.2 & 11.063 & 1 & 0.001 \\
\hline Marital status & & & & & 31.053 & 2 & 0.000 \\
\hline Single & 354 & 46.9 & 1422 & 47.8 & & & \\
\hline Married/remarried & 357 & 47.3 & 1189 & 39.9 & & & \\
\hline Divorced/widowed & 44 & 5.8 & 367 & 12.3 & & & \\
\hline Family history & 207 & 27.4 & 810 & 27.2 & 0.014 & 1 & 0.904 \\
\hline Health insurance & 334 & 44.2 & 1599 & 53.7 & 21.567 & 1 & 0.000 \\
\hline Referring persons & & & & & 0.616 & 1 & 0.433 \\
\hline Relatives & 748 & 99.1 & 2490 & 98.7 & & & \\
\hline Police and social affairs & 7 & 0.9 & 38 & 1.3 & & & \\
\hline \multicolumn{8}{|l|}{ Risk behaviours } \\
\hline Violent behaviours towards others & 40 & 5.3 & 794 & 26.7 & 158.448 & 1 & 0.000 \\
\hline Suicidal or self-injurious behaviours & 113 & 15.0 & 1041 & 35.0 & 112.687 & 1 & 0.000 \\
\hline Risk of self-harm & 359 & 47.5 & 2490 & 83.6 & 433.432 & 1 & 0.000 \\
\hline Risk to the safety of others & 96 & 12.7 & 1191 & 40.0 & 198.391 & 1 & 0.000 \\
\hline \multicolumn{8}{|l|}{ Insight } \\
\hline None & 238 & 31.5 & 2266 & 76.1 & 674.936 & 2 & 0.000 \\
\hline Partial & 318 & 42.1 & 605 & 20.3 & & & \\
\hline Complete & 199 & 26.4 & 107 & 3.6 & & & \\
\hline Initial diagnosis* & & & & & 396.042 & 3 & 0.000 \\
\hline F0* & 17 & 2.3 & 377 & 11.3 & & & \\
\hline $\mathrm{F} 2 *$ & 225 & 29.8 & 1715 & 57.6 & & & \\
\hline F3* & 361 & 47.8 & 766 & 25.7 & & & \\
\hline Other diagnosis & 152 & 20.1 & 160 & 5.4 & & & \\
\hline
\end{tabular}

Table 2. Demographic and clinical characteristics of the two groups (1). *Initial diagnosis was made in the outpatient department as soon as the psychiatrists finished assessing the conditions of the patients. F0: Organic, including symptomatic, mental disorders; F2: Schizophrenia, schizotypal and delusional disorders; F3: Mood [affective] disorders.

\begin{tabular}{|l|l|l|l|l|l|l|}
\hline & \multicolumn{2}{|l|}{$\begin{array}{l}\text { Voluntary admission } \\
(\mathbf{n = 7 5 5 )}\end{array}$} & \multicolumn{2}{l|}{$\begin{array}{l}\text { Involuntary } \\
\text { admission }(\mathbf{n = 7 8})\end{array}$} & \multicolumn{2}{l|}{ Statistics } \\
\cline { 2 - 8 } & Mean & SD & Mean & SD & Z & P \\
\hline Length of illness (months) & 107.71 & 109.68 & 126.69 & 139.02 & -1.210 & 0.226 \\
\hline Number of hospitalizations & 1.03 & 2.19 & 2.14 & 3.89 & -7.463 & 0.000 \\
\hline
\end{tabular}

Table 3. Demographic and clinical characteristics of the two groups (2).

considerable scope for discretion because there are no specific operational procedures or detailed regulations on the criteria, such as clarification of the timeframe considered (is it 'imminent' risk or prior risk?) or of the severity of the risk (is it mild, moderate or severe risk?) ${ }^{32,33}$, which may cause misuse or abuse of the criteria by psychiatrists $^{34,35}$. Furthermore, research has identified different interpretations of IA criteria among psychiatrists even though there are clear regulations in the local legislation ${ }^{34,36,37}$, which means that psychiatrists may be more inclined to make decisions according to their professional judgement but not the legal provisions ${ }^{34,36}$. Third, psychiatrists play central roles in balancing the interests of the public with protecting the legal rights of mental disorder patient $\mathrm{s}^{38-42}$, especially regarding circumstances in which patients do not present significant signs or clear risk of harming themselves or others ${ }^{34,40}$. Moreover, affected by traditional culture and legislation, Chinese families are burdened with the huge responsibility and obligation of taking care of and managing patients ${ }^{13,43,44}$. When a patient does not show a clear risk of harm to himself/herself or others, psychiatrists might practise 'defensive psychiatry' (i.e., 'a practice of decision-making that limits the psychiatrist's liability while protecting patients and others from potential harm' $)^{42,45}$ in response to the stubbornness of relatives who may be more likely or reluctant to seek IA services. 


\begin{tabular}{|c|c|c|c|}
\hline & P-value & \begin{tabular}{|l} 
Odds \\
ratio
\end{tabular} & 95\% C.I. \\
\hline \multicolumn{4}{|l|}{ Total $R^{2}=0.489, p<0.001$} \\
\hline \multicolumn{4}{|l|}{ Age (years) } \\
\hline$\leq 44$ & 0.026 & 1.000 & - \\
\hline $45-59$ & 0.825 & 1.034 & $0.771-1.385$ \\
\hline$\geq 60$ & 0.011 & 1.619 & $1.119-2.344$ \\
\hline \multicolumn{4}{|l|}{ Marital status } \\
\hline Single & 0.023 & 1.000 & - \\
\hline Married/remarried & 0.840 & 0.974 & $0.756-1.255$ \\
\hline Divorced/widowed & 0.014 & 1.735 & $1.119-2.689$ \\
\hline \multicolumn{4}{|l|}{ Insight } \\
\hline None & 0.000 & 1.000 & - \\
\hline Partial & 0.000 & 0.335 & $0.265-0.423$ \\
\hline Complete & 0.000 & 0.147 & $0.104-0.207$ \\
\hline Number of hospitalizations & 0.000 & 1.111 & $1.060-1.165$ \\
\hline Risk behaviours: Violent behaviours towards others & 0.000 & 4.815 & $3.220-7.201$ \\
\hline Risk behaviours: Suicidal or self-injurious behaviours & 0.000 & 2.917 & $2.259-3.768$ \\
\hline Risk behaviours: Risk of self-harm & 0.000 & 9.597 & $7.533-12.226$ \\
\hline Risk behaviours: Risk to the safety of others & 0.000 & 3.254 & $2.412-4.391$ \\
\hline \multicolumn{4}{|l|}{ Initial diagnosis* } \\
\hline F2* & 0.000 & 1.000 & - \\
\hline F0* & 0.144 & 1.597 & $0.852-2.994$ \\
\hline F3* & 0.000 & 0.467 & $0.363-0.602$ \\
\hline Other diagnosis & 0.000 & 0.317 & $0.225-0.449$ \\
\hline Constant & 0.105 & 0.795 & - \\
\hline
\end{tabular}

Table 4. Independent contributors to IA status (multiple logistic regression analysis). *Initial diagnosis was made in the outpatient department as soon as the psychiatrists finished assessing the conditions of the patients. F0: Organic, including symptomatic, mental disorders; F2: Schizophrenia, schizotypal and delusional disorders; F3: Mood [affective] disorders.

In summary, detailed regulations on IA risk criteria and appropriate training of clinicians are necessary to control the effects of non-medical factors on the IA rate ${ }^{20,46-48}$. Although this is an epidemiological investigation and does not include an evaluation of any particular intervention, it does pave the way for future research and policy proposals on the IA process (i.e., the formulation of a detailed operational method and flow to improve the implementation of the IA criteria). To improve the implementation of the new criteria, we are developing a new IA assessment scale and will present it in our other articles.

\section{Methods}

Design and participants. This investigation was designed to identify patterns of IA following the implementation of the new risk criteria and to lay the groundwork for formulating an IA assessment process, which would be used to evaluate the appropriateness of IA for psychiatric patients. This study was conducted in the tertiary specialized psychiatric service system in Shanghai because such hospitals provide most of the IA services to residents. Emergencies and patients needing IA services are sent to tertiary specialized psychiatric hospitals first, while the secondary and primary psychiatric hospitals usually provide services to outpatients, the community and individuals with chronic mental disorders. One tertiary specialized psychiatric hospital and 19 secondary specialized psychiatric hospitals were operating in Shanghai. SMHC is the only tertiary specialized psychiatric hospital with 24-hour outpatient services in Shanghai, and it is also the largest psychiatric hospital in China, receiving more than 2000 outpatient visits per day and containing approximately 990 psychiatric inpatient beds.

A total of 3864 patients were consecutively admitted to SMHC in the first 12 months and in the 30th and 48th months following the implementation of the new mental health law. The inclusion criteria were as follows: the participants were adult inpatients (18 years old and above) in SMHC during the study periods; the patients were hospitalized for more than one week; and the patients (or their guardians if necessary) could understand the content of the interview and sign a written informed consent form. The exclusion criteria were as follows: individuals admitted compulsorily based on China's revised Criminal Procedures Law (i.e., forensic patients); and patients' medical records were incomplete or unavailable at the time of data collection. For patients admitted more than once over the follow-up periods, each admission was considered separately.

Procedures and measures. Based on a review of the findings of related studies ${ }^{15,16}$, it was assumed that the IA rate would decline at the beginning of the implementation of the new legislation and remain relatively stable or rise gradually afterwards. Accordingly, this study was designed to investigate the IA pattern during the first year (i.e., from the $1^{\text {st }}$ to the $12^{\text {th }}$ months) and a few months in the next several years following the implementation 
of the new law (i.e., the $30^{\text {th }}$ and $48^{\text {th }}$ months depending on the situation of the study). The data were collected through the medical information system of the hospital so that the process of collecting a large amount of data would be more convenient and efficient. The inpatients' socio-demographic characteristics, such as gender, age, occupation, marital status, and health insurance, were extracted and recorded, and the clinical information of the inpatients was collected simultaneously (i.e., family history, referring persons, risk behaviours, insight, initial diagnosis, length of illness, and number of hospitalizations).

Psychiatrists whose professional titles were attending psychiatrists or above (i.e., chief psychiatrists and associate chief psychiatrists) with more than 5 years of experience in clinical practice made the initial diagnoses, evaluated the insight of the patients and recorded their risk behaviours at the time of admission. Diagnoses were based on the International Classification of Diseases $10^{\text {th }}$ revision (ICD-10); if more than one diagnosis was listed, the principal (first) diagnosis was recorded. According to the prior records in the electronic medical information system of SMHC, inpatients who were diagnosed with organic mental disorders (F00-F09), schizophrenia-related disorders (F20-29), or mood disorders (F30-39) accounted for the majority of all inpatients. Therefore, ICD-10 diagnoses at admission were divided into 4 groups: F0, F2, F3, and others.

The psychiatrists were required to record the insight of patients at admission using three main levels (i.e., complete, partial and no insight) to obtain a preliminary understanding of the patients' cognitive ability to evaluate their mental state. The patients' insight was subjectively evaluated by the psychiatrists according to the following questions: whether the patient believes that his/her abnormal experiences are symptoms; whether the patient believes his/her symptoms are attributed to a mental disorder; whether he/she believes that the disorder is psychiatric; whether he/she believes that psychiatric treatment might benefit him/her; and whether he would be willing to accept advice from a doctor regarding his/her treatment. The risk behaviours of the patients were also categorized into 4 groups according to the criteria of the IA legislation: violent behaviours against others, suicidal or self-injurious behaviours, risk of self-harm, and risk to the safety of others. The psychiatrists would select the relevant items in accordance with the patients' specific situations.

Statistical analysis. The data were analysed using SPSS version 17.0 (SPSS Inc., Chicago, IL, USA). A descriptive analysis of the frequency of IA was conducted. The comparison of the basic demographic and clinical characteristics between voluntary and involuntary patients was performed with one-way ANOVA, the Mann-Whitney U test, and the chi-square test, as appropriate. Multiple logistic regression including all the independent variables that differed significantly between the two groups (voluntary and involuntary admission groups) was used to assess the independent contributors to involuntary admission. The level of significance was set at 0.05 (two-tailed).

Ethical approval and informed consent. The Research Ethical Committee at the Shanghai Mental Health Center (IORG Number: IORG0002202; FWA Number: FWA00003065) approved the study. The director of the participating psychiatric hospital approved the collection of data from electronic information systems and case files at the institution. All the personal information of the patients and psychiatrists was properly protected in the analysis. All the research was performed in accordance with relevant regulations, and written informed consent was obtained from all the participants.

\section{Data availability}

The datasets generated during and/or analysed during the current study are available from the corresponding author on reasonable request.

Received: 10 January 2019; Accepted: 8 October 2019;

Published online: 24 October 2019

\section{References}

1. Priebe, S. et al. Patients' views and readmissions 1 year after involuntary hospitalisation. Br J Psychiatry. 194, 49-54 (2009).

2. van der Post, L. F. et al. Patient perspectives and the risk of compulsory admission: the Amsterdam Study of Acute Psychiatry V. Int J Soc Psychiatry. 60, 125-33 (2014).

3. Eytan, A., Chatton, A., Safran, E. \& Khazaal, Y. Impact of psychiatrists' qualifications on the rate of compulsory admissions. Psychiatr Q. 84, 73-80 (2013).

4. Kallert, T. W., Glöckner, M. \& Schützwohl, M. Involuntary vs. voluntary hospital admission. A systematic literature review on outcome diversity. Eur Arch Psychiatry Clin Neurosci. 258, 195-209 (2008).

5. Dhanda, A. \& Narayan, T. Mental health and human rights. Lancet. 370, 1197 (2007).

6. Pan, Z. D., Xie, B. \& Zheng, Z. P. A survey on psychiatric hospital admission and relative factors in China (in Chinese). Journal of Clinical Psychological Medicine. 13, 270-272 (2003).

7. Gou, L. et al. Frequency of involuntary admissions and its associations with demographic and clinical characteristics in China. Arch Psychiatr Nurs. 28, 272-276 (2014).

8. Lay, B., Nordt, C. \& Rössler, W. Variation in use of coercive measures in psychiatric hospitals. Eur Psychiat. 26, 244-251 (2011).

9. Mulder, C. L. et al. Changing patterns in emergency involuntary admissions in the Netherlands in the period 2000-2004. Int J Law Psychiatry. 31, 331-336 (2008).

10. Cheng., H. H., Phillips, M. R., Cheng, H., Chen, X. D. \& Zhu, Z. L. Mental health law of the People's Republic of China (English translation with annotations). Shanghai Archives of Psychiatry. 24, 305-321 (2012).

11. United Nations General Assembly (46/119). The protection of person with mental illness and the improvement of mental health care, http://www.un.org/documents/ga/res/46/a46r119.htm (1991).

12. Department of Mental Health and Substance Dependence (WHO). Mental health legislation: ten basic principles. Geneva: WHO (1996).

13. Zhou, J. S. et al. Voluntary and Involuntary Psychiatric Admissions in China. Psychiatr Serv. 66, 1341-1346 (2015).

14. Fiorillo, A. et al. How to improve clinical practice on involuntary hospital admissions of psychiatric patients: Suggestions from the EUNOMIA study. Eur Psychiat. 26, 201-207 (2011). 
15. Salize, H. J. \& Dressing, H. Epidemiology of involuntary placement of mentally ill people across the European Union. Br J Psychiatry. 184, $163(2004)$

16. Topiwala, A., Wang, X. P. \& Fazel, S. Chinese forensic psychiatry and its wider implications. Journal of Forensic Psychiatry \& Psychology. 23, 1-6 (2012).

17. Jacobsen, T. B. Involuntary treatment in Europe: different countries, different practices. Curr Opin Psychiat. 25, 307 (2012).

18. Xiang, Y. T. et al. Association of insight with sociodemographic and clinical factors, quality of life, and cognition in Chinese patients with schizophrenia. Compr Psychiatry. 53, 140-144 (2012).

19. Van der Post, L. et al. Involuntary Admission of Emergency Psychiatric Patients: Report From the Amsterdam Study of Acute Psychiatry. Psychiatr Serv. 60, 1543-1546 (2009).

20. Hung, Y. Y., Chan, H. Y. \& Pan, Y. J. Risk factors for readmission in schizophrenia patients following involuntary admission. Plos One. 12, $\mathrm{e} 0186768$ (2017).

21. Hustoft, K. et al. Predictors of involuntary hospitalizations to acute psychiatry. International Journal of Law \& Psychiatry. 36, 136-143 (2013)

22. Woo, B. K. et al. Factors associated with frequent admissions to an acute geriatric psychiatric inpatient unit. J Geriatr Psychiatry Neurol. 19, 226-230 (2006).

23. Katsakou, C. \& Priebe, S. Outcomes of involuntary hospital admission-a review. Acta Psychiatr Scand. 114, 232-241 (2006).

24. Indu, N. V., Vidhukumar, K. \& Sarma, P. S. Determinants of compulsory admissions in a state psychiatric hospital-Case control study. Asian Journal of Psychiatry. 35, 141-145 (2018).

25. Srikumar, S. \& Orrell, M. W. Age and compulsory admission. Int J Geriatr Psychiatry. 10, 611-615 (1995).

26. Patel, V. et al. The magnitude of and health system responses to the mental health treatment gap in adults in India and China. Lancet. 388, 3074-3084 (2017).

27. Lorant, V., Depuydt, C., Gillain, B., Guillet, A. \& Dubois, V. Involuntary commitment in psychiatric care: what drives the decision? Soc Psychiatry Psychiatr Epidemiol. 42, 360-365 (2007).

28. Chen, S. Q., Xie, F. \& Zhang, G. Q. Investigation and analysis of the current status of doctor team in Shanghai mental health professional institutions. Sichuan Mental Health. 1, 75-77 (2015).

29. Ma, H. Integration of hospital and community services-the ' 686 Project'-is a crucial component in the reform of China's mental health services. Shanghai Archives of Psychiatry. 24, 172-174 (2012).

30. Lin, H., Liang, Z. G. \& Liang, P. Severe Mental Illness Stigma Investigation and Intervention. Chinese General Practice. 13, 1551-1553 (2014).

31. Li, C. \& Sun, H. Stigma and Related Factors of Psychiatric Patients' Family Members. China Journal of Health Psychology. 3, 343-347 (2016).

32. Phillips, M. R. et al. China's new mental health law: reframing involuntary treatment. Am J Psychiatry. 170, 588-591 (2013).

33. Shao, Y., Wang, J. \& Xie, B. The first mental health law of China. Asian Journal of Psychiatry. 13, 72-74 (2015).

34. Feiring, E. \& Ugstad, K. N. Interpretations of legal criteria for involuntary psychiatric admission: a qualitative analysis. BMC Health Services Research. 14, 1-10 (2014).

35. Feng, J. et al. The implementation of China's Mental health law-defined risk criteria for involuntary admission: A national crosssectional study of involuntarily hospitalized patients. Front Psychiatry. 9, 560 (2018).

36. Fistein, E. C., Clare, I. C., Redley, M. \& Holland, A. J. Tensions between policy and practice: A qualitative analysis of decisions regarding compulsory admission to psychiatric hospital. Int J Law Psychiatry. 46, 50-57 (2016).

37. Hashmi, A., Shad, M., Rhoades, H., Grover, M. \& Parsaik, A. K. Involuntary Detention: Comparison of Clinical Practices of Psychiatry Residents and Faculty. Academic Psychiatry. 38, 619-622 (2014).

38. Shao, Y., Xie, B. \& Wu, Z. Psychiatrists' attitudes towards the procedure of involuntary admission to mental hospitals in China. Int $J$ Soc Psychiatry. 58, 440-447 (2012).

39. Lepping, P., Steinert, T., Gebhardt, R. P. \& Röttgers, H. R. Attitudes of mental health professionals and lay-people towards involuntary admission and treatment in England and Germany-a questionnaire analysis. Eur Psychiat. 19, 91-95 (2004).

40. Kjellin, L., Høyer, G., Engberg, M., Kaltiala-Heino, R. \& Sigurjónsdóttir, M. Differences in perceived coercion at admission to psychiatric hospitals in the Nordic countries. Soc Psychiatry Psychiatr Epidemiol. 41, 241-247 (2006).

41. Litwack, T. R. Assessments of dangerousness: Legal, research, and clinical developments. Administration and Policy in Mental Health and Mental Health Services Research. 21, 361-377 (1994).

42. Sattar, S. P., Pinals, D. A., Din, A. U. \& Appelbaum, P. S. To Commit or Not to Commit: The Psychiatry Resident as a Variable in Involuntary Commitment Decisions. Academic Psychiatry. 30, 191-195 (2006).

43. Fan, R. \& Wang, M. Taking the Role of the Family Seriously in Treating Chinese Psychiatric Patients: A Confucian Familist Review of China's First Mental Health Act. J Med Philos. 40, 387-399 (2015).

44. Ma, Z. Intimate life politics: the subject of family responsibility and mental health legislation (in Chinese). The Ideological Front. 40, $42-49$ (2014).

45. Brown, J. \& Rayne, J. T. Some ethical considerations in defensive psychiatry: A case study. Am J Orthopsychiatry. 59, 534-541 (2010).

46. Silva, N. C., Bassani, D. G. \& Palazzo, L. S. A case-control study of factors associated with multiple psychiatric readmissions. Psychiatr Serv. 60, 786-791 (2009).

47. Shao, Y. \& Xie, B. Operationalizing the involuntary treatment regulations of China's new mental health law. Shanghai Archives of Psychiatry. 25, 384-386 (2013).

48. Sashidharan, S. P. \& Saraceno, B. Is psychiatry becoming more coercive? Bmj Clinical Research. 357, j2904 (2017).

\section{Acknowledgements}

This research was supported by grants from the following: (1) the National Science \& Technology Pillar Program during the 12th Five-Year Plan of China (2012BAK16B04, PI: Bin Xie), (2) the National Health and Family Planning Commission projects on mental disease prevention and control (NHFPC DPC-MH 2016-53, PI: Bin Xie), (3) the Shanghai Three-Year Public Health Action Plan (fourth round) - senior overseas research team training program (GWTD2015509, PI: Bin Xie), and (4) the Shanghai Municipal Health and Family Planning Commission (psychiatry) key discipline(2017ZZ02021, PI: Min Zhao).

\section{Author contributions}

H.J.M., B.X. and Y.S. participated in the planning, execution, and analysis of the study. Z.P.X. and B.X. participated in the design of the study. H.J.M. and B.X. performed the data analysis and wrote the main manuscript. B.X., Y.S., J.J.H. and Z.P.X. provided critical revisions to the article. All the authors have reviewed the manuscript and approved the final version submitted.

\section{Competing interests}

The authors declare no competing interests. 
Additional information

Correspondence and requests for materials should be addressed to Z.-P.X.

Reprints and permissions information is available at www.nature.com/reprints.

Publisher's note Springer Nature remains neutral with regard to jurisdictional claims in published maps and institutional affiliations.

(c) (i) Open Access This article is licensed under a Creative Commons Attribution 4.0 International License, which permits use, sharing, adaptation, distribution and reproduction in any medium or format, as long as you give appropriate credit to the original author(s) and the source, provide a link to the Creative Commons license, and indicate if changes were made. The images or other third party material in this article are included in the article's Creative Commons license, unless indicated otherwise in a credit line to the material. If material is not included in the article's Creative Commons license and your intended use is not permitted by statutory regulation or exceeds the permitted use, you will need to obtain permission directly from the copyright holder. To view a copy of this license, visit http://creativecommons.org/licenses/by/4.0/.

(C) The Author(s) 2019 